\title{
Assessment of Occupational Stress Among Oral and Maxillofacial Surgeons and Residents in Saudi Arabia: A Cross-Sectional Study
}

This article was published in the following Dove Press journal:

Advances in Medical Education and Practice

\author{
Mohammed Alkindi $\mathbb{D}^{\prime}$ \\ Osama Alghamdi' \\ Hourya Alnofaie $\mathbb{1}^{2,3}$ \\ Ziyad AlHammad ${ }^{4}$ \\ Mohammed Badwelan (D) \\ Sahar Albarakati (iD ${ }^{5}$ \\ 'Oral and Maxillofacial Surgery \\ Department, College of Dentistry, King \\ Saud University, Riyadh, Saudi Arabia; \\ ${ }^{2}$ Oral and Maxillofacial Surgery Division, \\ Basic Dental Sciences Department, \\ College of Dentistry, Princess Nourah \\ Bint Abdulrahman University, Riyadh, \\ Saudi Arabia; ${ }^{3}$ Saudi Board of Oral and \\ Maxillofacial Surgery, Saudi Commission \\ for Health Specialties, Riyadh, Saudi \\ Arabia; ${ }^{4}$ Oral and Maxillofacial Surgery, \\ Ministry of Health, Riyadh, Saudi Arabia; \\ ${ }^{5}$ Department of Pediatric Dentistry and \\ Orthodontics, College of Dentistry, King \\ Saud University, Riyadh, Saudi Arabia
}

Correspondence: Mohammed Alkindi Oral and Maxillofacial Surgery Department, College of Dentistry, King Saud University, P. O. Box 60169, Riyadh II545, Saudi Arabia Tel +966(I)46984I7

Email Malkindi@ksu.edu.sa
Purpose: Considering the important role of oral and maxillofacial surgeons in healthcare services and the stressful nature of their job, this study aimed to assess the occupational stress among oral and maxillofacial surgeons and residents in Saudi Arabia.

Materials and Methods: Cross-sectional questionnaires were developed, and they included the perceived stress scale and questions about potential sources of stress. A sample size of 180 was determined using a 0.05 level of significance and a precision of $\pm 8 \%$. The survey was distributed using a consecutive non-random sampling method to all oral and maxillofacial surgeons and residents in all regions in Saudi Arabia from May to December 2019.

Results: One hundred and seventy-two responses were received. Males were the predominant gender. The perceived stress scale revealed a moderate stress level among surgeons and residents. However, residents had a significantly higher score $(P=0.005)$. Increased working days were significantly associated with higher stress levels $(P=0.006)$. Long on-call periods were significantly and positively correlated with increased stress levels among residents since their work schedule was not flexible $(P=0.000)$. The majority of surgeons and residents believe that they have unconducive and stressful work environments and that working as a maxillofacial surgeon is stressful.

Conclusion: The study results suggest that there is increased occupational stress among oral and maxillofacial surgeons and residents in Saudi Arabia. This study highlights the need for stress management programs to minimize stress factors at the workplace and to ensure a healthy working environment for the practitioners.

Keywords: stress, burnout, oral and maxillofacial surgery, surgeons, residents, Saudi Arabia

\section{Introduction}

Occupational stress occurs when job-related factors interact with the individual's factors, and result in a change in the individual's psychological and/or physiological state. ${ }^{1}$ Some level of stress can be positive and motivating and can lead to increased performance in the workplace. ${ }^{2}$ However, excessive and cumulative stress results in poor performance, sickness, and eventually burnout. ${ }^{2}$ Burnout is recognized by the World Health Organization's International Classification of Diseases as a worldwide epidemic which is a distinct state of psychological stress due to an individual's occupation. ${ }^{3,4}$ Professional burnout may impair the quality of life and quality of patient care by increasing the risk of medical errors. ${ }^{5}$

Healthcare professionals are usually at risk of burnout. ${ }^{6}$ A systematic review was conducted in 2017, which reported moderate-to-high estimates of self-reported 
burnout among healthcare professionals in Arab countries similar to prevalence estimates in other developed countries worldwide. $^{6}$

Dentistry is known to be one of the most stressful professions and the overall level of stress depends on the patient-dentist relationship, job satisfaction, high work demands, exposure to toxic substances, and long working hours. ${ }^{7,8}$ Oral and maxillofacial surgery (OMS) is one of nine dental specialties recognized internationally and by the American Dental Association (ADA). The nature of OMS practice is similar to that of other medical surgical specialties. This is because surgeons in these specialties have similar duties. They work on call, perform inpatient care, work in outpatient clinics, and perform major surgical procedures under sedation and/or general anesthesia. The specialty of OMS requires more training than any other dental specialty, averaging 6-12 years of higher education. After this rigorous training program, the practitioner works with patients who are under extreme physical and emotional distress from pain, traumatic injury, disfiguring tumors, and facial deformities (both functional and aesthetic). ${ }^{9}$ Furthermore, these patients, in addition to being in pain, are often extremely fearful of the procedures to which they will undergo. ${ }^{9}$ Thus, the specialty of OMS can be more stressful than other dental specialties. This is supported by the study of Humphris et al, ${ }^{10}$ who revealed that stress among dentists working in OMS was significantly higher than that among dentists working in other dental specialties. Moreover, the majority of Brazilian oral and maxillofacial (OM) surgeons have unsatisfactory working conditions and low personal accomplishments. ${ }^{11,12}$ Surprisingly, a single study has found lower burnout risk among OM surgeons when compared with general dental practitioners. ${ }^{13}$ This study was carried on Dutch OM surgeons and the reasons which contributed to lower levels of stress were argued to be that OM surgeons have high work motivation knowing that OMS demands long study periods and seem to have professional support due to partnerships and the continuous medical technical safety control since most of their work is in hospitals. ${ }^{13}$

Residency training programs that provide adequate medical education are essential since they help to provide proper patient care. However, residency is considered to be a difficult and stressful stage in the career of every healthcare practitioner. $^{14}$ Residents, being juniors, are often subjected to prolonged working hours, sleep deprivation, uncontrolled schedules, high job demands, and inadequate personal time. ${ }^{15}$ Residency may also negatively affect the quality of life of residents and cause them to have family problems and develop psychiatric or sleep disorders. $^{16,17}$

Alosaimi et $\mathrm{al}^{18}$ conducted a study involving medical residents in Saudi Arabia and reported comparable or slightly higher risk of perceived stress than that reported among residents worldwide. Shapiro et al $^{19}$ assessed the relationship between shame events and burnout among OMS residents in the United States and they found a strong relationship between these events and increased burnout and stress levels. Brazilian OMS residents showed more burnout than the surgeons and this was attributed to the fact that residents are treated as students undergoing a learning process, with extenuating work days and obligatory tasks to perform; additionally, they must behave as complete professionals from whom responsibility, skill and efficiency are expected. ${ }^{11}$ Moderate-to-severe anxiety, which can be directly associated with high stress levels, was found among most of the OMS residents. ${ }^{20}$ Female residents were more likely to have severe anxiety than males. This was hypothesized to be due to fear of gender-based discrimination in such a male dominant surgical specialty. $^{21}$

To the best of our knowledge, no study has evaluated stress and burnout among OMS residents and/or surgeons in Saudi Arabia. Considering the integral role of OMS in both dental and medical healthcare services, this study aimed to assess occupational stress among oral and maxillofacial surgeons and residents in Saudi Arabia.

\section{Materials and Methods}

The cross-sectional design was adopted in this study with the following two target groups: (1) oral and maxillofacial (OM) surgeons and (2) oral and maxillofacial surgery (OMS) residents in Saudi Arabia.

\section{Questionnaires}

Both web- and paper-based cross-sectional surveys were developed. The survey was designed to have three main sections: (1) personal information, 15 questions, (2) potential sources of stress, 20 questions, and (3) perceived stress scale (PSS), 10 questions. ${ }^{22}$ The first section included different personal and professional questions about gender, age, academic level, training program country and years, working hours, on-call duty, number of chairs, and general anesthesia cases. The second section consisted of questions on the different sources of stress and it was developed from a similar previous study. ${ }^{23}$ Participants were 
asked to choose from a scale ranging from 0 to 3 as follows: (0) not applicable, (1) disagree, (2) fair, and (3) agree. The third section consisted of 10 questions from the perceived stress scale (PSS) survey described by Cohen et $\mathrm{al}^{22}$ which evaluates the level of stress experienced by individuals during the previous month. Participants were asked random questions about their perception, feeling, and thoughts about stressors and they had to answer using a Likert-type scale from 0 to 4 as follows: (0) never, (1) almost never, (2) sometimes, (3) fairly often, and (4) very often. The PSS score was calculated by adding the scores for all the individual questions, and higher scores indicated higher levels of stress.

Ethical approval was obtained from the Institutional Review Boards (IRB) of King Saud University and College of Dentistry Research Centre (CDRC) with numbers E-19-4014 and FR 0509, respectively.

\section{Participants}

The study involved two groups in Saudi Arabia: OM surgeons and OMS residents. Participants who were OM surgeons were included if they were practicing in Saudi Arabia while participants who were OMS residents were included if they were enrolled in any of the following accredited OMS academic training programs in Saudi Arabia: (1) Saudi Board, Saudi Commission for Health Specialties, (2) Doctorate of Science (DSc.), King Saud University, or (3) Master of Science (MSc.), Riyadh Alelm University. The residents were excluded if they were either shadowing residents or service residents.

According to Lwanga and Lemeshow, ${ }^{24}$ the sample size was calculated to be 150 study subjects by assuming that $50 \%$ of both surgeons and residents will have occupational stress and by using a precision of $\pm 8 \%$ at 0.05 level of significance. Since we anticipated $20 \%$ non-response, the target sample size was calculated to be 180 subjects.

Due to the limited number of OMS residents and surgeons in Saudi Arabia, a consecutive non-random sampling method was used where all subjects were approached either directly or via emails and social media to participate in this study.

A list of all the names of surgeons and residents was retrieved from the Saudi Society of Oral and Maxillofacial Surgery. This list was further divided into several different lists according to hospitals and regions in Saudi Arabia to ensure best coverage as possible. These lists were followed precisely during the data collection phase and were checked regularly until the appropriate sample size was obtained.

A pilot study was carried out on 20 participants before the initial data collection phase to ensure the validity of the survey.

Data collection was conducted from May to December 2019. Target groups were directly approached with either a hardcopy survey or an electronic survey on tablet devices either at their academic institutions or hospitals. Additionally, the online link for the survey was sent via emails, Twitter, and WhatsApp to all surgeons and residents in all regions in Saudi Arabia. Although different methods were used to collect the responses, we controlled for response duplication. Informed consent was obtained from all participants based on the guidelines of the Institutional Review Board (IRB) of King Saud University. A cover page was attached in the beginning of the survey which stated the research's objectives and members and included an agreement question to participate voluntarily to this study.

\section{Statistical Analysis}

Data were analyzed using SPSS version 21.0 (IBM Inc., USA) statistical software. Descriptive statistics (frequencies, percentages, mean, and standard deviation) were used to describe the categorical and quantitative variables. The rank-biserial Spearman's test was used to test for correlations between the severity scores of occupational stressrelated questions and other study variables. A Student's $t$-test was used for the independent samples of parametric variables with two average means. An analysis of variance (ANOVA) test was used for independent samples of parametric variables with more than two mean values. Statistical significance was set a p-value $<0.01$.

\section{Results}

A total of 172 responses were received from 121 (70.3\%) surgeons and $51(29.7 \%)$ residents.

\section{Needed Personal Information}

Demographic data were analyzed (Table 1). The participants were predominantly males $(76.2 \%)$. Majority of the surgeons were between the ages of 31 and 40 years old (43.0\%), followed by those between 41 and 50 years old $(19.2 \%)$, whereas most of the residents were either 30 years old or less $(16.9 \%)$, followed by those between the ages of 31-40 years old (12.8\%). Most of the surgeons (n $=121$ ) were trained in programs than lasted for more than 
Table I Answers to Personal Information Questions

\begin{tabular}{|c|c|c|c|c|c|c|}
\hline \multirow[t]{2}{*}{ Variables } & \multicolumn{2}{|c|}{ Surgeons $(N=|2|)$} & \multicolumn{2}{|c|}{ Residents ( $N=5 \mathrm{I})$} & \multirow[t]{2}{*}{ Total } & \multirow{2}{*}{$\begin{array}{l}\text { Significance } \\
P<0.0 \text { I }\end{array}$} \\
\hline & $\mathbf{N}$ & $\%$ & $\mathbf{N}$ & $\%$ & & \\
\hline \multicolumn{7}{|l|}{ Age } \\
\hline Less than 30 & 0 & $0.0 \%$ & 29 & $56.9 \%$ & $29(16.9 \%)$ & $<0.001$ \\
\hline $31-40$ & 74 & $61.2 \%$ & 22 & $62.9 \%$ & $96(55.8 \%)$ & \\
\hline $4 \mid-50$ & 33 & $27.3 \%$ & 0 & $0.0 \%$ & $33(19.2 \%)$ & \\
\hline $5 I-60$ & 13 & $10.7 \%$ & 0 & $0.0 \%$ & $13(7.6 \%)$ & \\
\hline More than 60 & 1 & $0.8 \%$ & 0 & $0.0 \%$ & I $(0.6 \%)$ & \\
\hline \multicolumn{7}{|l|}{ Gender } \\
\hline Male & 96 & $79.3 \%$ & 35 & $68.6 \%$ & $13 \mid(76.2 \%)$ & $<0.001$ \\
\hline Female & 25 & $20.7 \%$ & 16 & $31.4 \%$ & $4 \mathrm{l}(23.8 \%)$ & \\
\hline \multicolumn{7}{|l|}{ Nationality } \\
\hline Saudi & 63 & $52.1 \%$ & 48 & $94.1 \%$ & III (64.5\%) & $<0.001$ \\
\hline Non-Saudi & 58 & $47.9 \%$ & 3 & $5.9 \%$ & 61 (35.5\%) & \\
\hline \multicolumn{7}{|l|}{ Academic Qualification } \\
\hline BDS & 25 & $13.7 \%$ & 51 & $87.9 \%$ & $76(31.7 \%)$ & $<0.001$ \\
\hline MSc & 48 & $26.4 \%$ & 7 & $12.1 \%$ & 55 (22.9\%) & \\
\hline $\mathrm{PhD} / \mathrm{DSc}$ & 19 & $10.4 \%$ & 0 & $0.0 \%$ & 19 (7.9\%) & \\
\hline Board & 49 & $26.9 \%$ & 0 & $0.0 \%$ & 49 (20.4\%) & \\
\hline Fellowship & 32 & $17.6 \%$ & 0 & $0.0 \%$ & 32 (I3.3\%) & \\
\hline Others & 9 & $4.9 \%$ & 0 & $0.0 \%$ & 9 (3.8\%) & \\
\hline
\end{tabular}

five years $(37.2 \%)$, while other surgeons were trained in programs that lasted for five years $(26.4 \%)$. For the multiple-choice question on the training country, many of the surgeons selected Saudi Arabia (29.2\%), followed by those who selected other Arab countries (25.5\%) and Europe (19.7\%), while only $11.7 \%$ of the surgeons trained in North America. The years of experience of the surgeons varied; majority (35.5\%) had 9-15 years of experience, followed by those who had 3-8 years (33.1\%) of experience, whereas only $9.9 \%$ and $5.8 \%$ had between $16-25$ and more than 25 years of experience, respectively.

Regarding the residents $(n=51), 40$ of those who answered the survey were Saudi Board residents (78.4\%), eight were DSc residents $(15.7 \%)$, and three were MSc residents (5.9\%). The Saudi Board and DSc programs are five-year residency programs, while the MSc program is a three-year academic program. Moreover, most of the residents who completed the survey were in their third year $(27.5 \%)$ and the least were in their first year (13.7\%).

Concerning the institution of practice, majority of the surgeons and residents practice in the Ministry of Health hospitals $(34.2 \%)$, followed by those who practice in the academic sector $(31.6 \%)$. The professional details of surgeons and residents in the current institution of practice are presented in Table 2. Most surgeons and residents work five days/week with an on-call duty of one week/ month. However, $25.5 \%$ of the residents reported that they work seven days/week. Increased working hours was observed among the residents; 38 residents out of 51 work 45 hours and more per week. Additionally, approximately $39 \%$ of both surgeons and residents have three or more chairs/patients in their workplace. Most of the surgeons $(24.0 \%)$ perform more than eight surgeries under general anesthesia per month, while most of the residents $(37.3 \%)$ perform only three to five surgeries. Fifteen percent of surgeons seem not to work in operating rooms, while only $3.9 \%$ of the residents do not work in operating rooms (Table 2).

\section{Potential Sources of Stress}

The answers of participants to the second section of the survey are presented in Tables 3 and 4. The majority of surgeons and residents were significantly stressed by paperwork, administrative duties, and prolonged on-call periods and working hours. Residents were significantly more burned out by long working hours and constant work pressure when compared to surgeons $(P=0.003)$. Additionally, among residents, longer on-call periods were significantly and positively correlated with increased 
stress as their work schedule was not flexible $(P=0.000, r$ $=0.564)$. Furthermore, most of the trainees $(37.3 \%)$ believe that the lack of training opportunities contributes to their stress. Those who were trained in programs with shorter durations felt more stressed due to lack of training opportunities $(P=0.003)$.

Most respondents did not have communication and/or language problems when communicating with patients. However, non-Saudi surgeons were more stressed due to their inability to communicate effectively with patients $(P=$ 0.007). Both groups reported increased frustration when performing clinical tasks on difficult or uncooperative patients. This frustration was mostly reported by surgeons (62.8\%) compared to residents $(37.3 \%)$. It was statistically significant that surgeons and subjects with less working hours felt more frustrated when treating uncooperative patients in the clinic $(P=0.004)$ and $(P=0.008)$, respectively. However, emergency treatment was not stressful or upsetting to either of the two groups. The results also demonstrated that surgeons and residents are mostly stressed due to fear of poor surgical outcomes. In contrast to residents, most surgeons believed that the expectations of their patients regarding surgical outcomes were unrealistic $(P=0.001)$.

Both groups reported general satisfaction regarding the level of respect they receive from patients and colleagues. However, residents were less satisfied with the level of respect the receive from seniors, colleagues, and juniors $(P$ $=0.004)$. In addition, participants with more working hours had more staff-related problems $(P=0.007)$. In terms of job salary, surgeons mostly agreed (46.3\%) that their profession ensures financial security, while $39.2 \%$ of the residents disagreed. Younger participants as well as surgeons with less experience were less satisfied with their job salary and financial security $(P=0.002)$. Regarding the provision of modern surgical technology in the field, residents $(45.1 \%)$ were more satisfied than surgeons $(38.0 \%)$. Both groups agreed that working on either interesting or new cases in the operating room is enjoyable.

Most participants were concerned about contracting an infection at the workplace. The lack of clear communication with other dental or medical specialties was found to be stressful to both groups. Finally, all participants agreed that they have unconducive and stressful work environments and that working as a maxillofacial surgeon is stressful.

\section{Perceived Stress Scale}

The results of the global measure of perceived stress using the perceived stress scale for the surgeons and residents are presented in Table 5. The results show that majority of the participants in both groups were sometimes upset because of the occurrence of an unexpected incident. Approximately, $30.5 \%$ of surgeons were sometimes unable to control the important things in their lives, whereas most residents were equally or very often unable to do the same $(27.5 \%)$. While residents were often nervous or stressed $(37.3 \%)$, surgeons rarely felt nervous or stressed $(40.5 \%)$. Most surgeons (37.2\%) and residents (47.1\%) were fairly often confident in their ability to handle personal problems. Although majority of the surgeons and residents believe that sometimes they were unable to cope with challenges (43.0\% and $47.1 \%$, respectively), they were fairly often able to control irritations in their lives (36.4\% and $35.3 \%$, respectively).

Our results also revealed that a considerable number of participants believed they could not cope with challenges or overcome difficulties. Additionally, they believe that sometimes they were angry because of issues that were out of their control. Compared to surgeons, most residents felt that most of the challenges they faced were difficult to overcome $(\mathrm{P}=0.001)$.

The perceived stress score was calculated and determined for both groups. ${ }^{22}$ The mean scores for surgeons and residents were 17.51 and 20.61, respectively. There was a significant difference in the mean PSS total score between surgeons (mean $(\mathrm{M})=17.51$, standard deviation $(\mathrm{SD})=6.845)$ and residents $(\mathrm{M}=20.61, \mathrm{SD}=5.575)(P=$ $0.005)$. Table 6 shows that majority of the surgeons and residents experience relatively moderate levels of stress. Among the OMS residents, increased working days were significantly associated with a higher stress level in PSS categories $(P=0.006, r=0.380)$.

\section{Discussion}

Oral and maxillofacial surgery (OMS) is an important specialty. It involves diagnosis and clinical and surgical treatment of traumatic, congenital, developmental, and iatrogenic lesions in the oral and maxillofacial complex. ${ }^{25}$ Dentists have been selected as the medical professionals more likely to be exposed to severe stress, burnout, failed marriages, depression, substance abuse, and commit suicide. ${ }^{9}$ However, with OMS being a particularly highstress specialty of dentistry, ${ }^{9}$ describing the details of stress and burnout and investigating the possible factors is crucial. Oral and maxillofacial (OM) surgeons experience stress due to the nature of their work and other predisposing characteristics. ${ }^{9}$ Occupational factors 
Table 2 Answers to Professional Questions About the Workplace

\begin{tabular}{|c|c|c|c|c|c|c|}
\hline \multirow[t]{2}{*}{ Variables } & \multicolumn{2}{|c|}{ Surgeons $(N=|2|)$} & \multicolumn{2}{|c|}{ Residents ( $N=5 \mathrm{I})$} & \multirow[t]{2}{*}{ Total } & \multirow{2}{*}{$\begin{array}{l}\text { Significance } \\
P<0.01\end{array}$} \\
\hline & $\mathbf{N}$ & $\%$ & $\mathbf{N}$ & $\%$ & & \\
\hline \multicolumn{7}{|l|}{ Working Days } \\
\hline 3 days/week & 3 & $2.5 \%$ & 0 & $0.0 \%$ & $3(1.7 \%)$ & $<0.001$ \\
\hline 4 days/week & 8 & $6.6 \%$ & 0 & $0.0 \%$ & $8(4.7 \%)$ & \\
\hline 5 days/week & 76 & $62.8 \%$ & 31 & $60.8 \%$ & 107 (62\%) & \\
\hline 6 days/week & 30 & $24.8 \%$ & 7 & $13.7 \%$ & 37 (21.5\%) & \\
\hline 7 days/week & 4 & $3.3 \%$ & 13 & $25.5 \%$ & $17(9.9 \%)$ & \\
\hline \multicolumn{7}{|l|}{ Working Hours } \\
\hline 30 or less/week & 9 & $7.4 \%$ & 2 & $3.9 \%$ & II (6.4\%) & $<0.001$ \\
\hline $35 /$ week & 14 & $11.6 \%$ & 3 & $5.9 \%$ & $17(9.9 \%)$ & \\
\hline 40/week & 41 & $33.9 \%$ & 8 & $15.7 \%$ & $49(28.5 \%)$ & \\
\hline 45/week & 34 & $28.1 \%$ & 19 & $37.3 \%$ & $53(30.8 \%)$ & \\
\hline 50 or more/week & 23 & $19.0 \%$ & 19 & $37.3 \%$ & $42(24.4 \%)$ & \\
\hline \multicolumn{7}{|l|}{ On-Calls } \\
\hline None & 21 & $17.4 \%$ & 1 & $2.0 \%$ & $22(12.8 \%)$ & $<0.001$ \\
\hline 24 hours/week & 9 & $7.4 \%$ & 5 & $9.8 \%$ & 14 (8.1\%) & \\
\hline I week/month & 60 & $49.6 \%$ & 30 & $58.8 \%$ & $90(52.3 \%)$ & \\
\hline 2 weeks/month & 22 & $18.2 \%$ & 12 & $23.5 \%$ & $34(19.8 \%)$ & \\
\hline More than 2 weeks/month & 9 & $7.4 \%$ & 3 & $5.9 \%$ & $12(7.0 \%)$ & \\
\hline \multicolumn{7}{|l|}{ Chairs/Patient } \\
\hline I chair/patient & 43 & $35.5 \%$ & 11 & $21.6 \%$ & 54 (31.4\%) & $<0.001$ \\
\hline 2 chairs/patient & 30 & $24.8 \%$ & 20 & $39.2 \%$ & $50(29.1 \%)$ & \\
\hline 3 ore more chairs/patient & 48 & $39.7 \%$ & 20 & $39.2 \%$ & $68(39.5 \%)$ & \\
\hline \multicolumn{7}{|l|}{ General Anesthesia Cases } \\
\hline None & 19 & $15.7 \%$ & 2 & $3.9 \%$ & $21(12.2 \%)$ & $<0.001$ \\
\hline Less than 3 cases & 18 & $14.9 \%$ & 3 & $5.9 \%$ & $21(12.2 \%)$ & \\
\hline $3-5$ cases & 27 & $22.3 \%$ & 19 & $37.3 \%$ & $46(26.7 \%)$ & \\
\hline $6-8$ cases & 28 & $23.1 \%$ & 12 & $23.5 \%$ & $40(23.3 \%)$ & \\
\hline More than 8 cases & 29 & $24.0 \%$ & 15 & $29.4 \%$ & $44(25.6 \%)$ & \\
\hline
\end{tabular}

include, among others, long required training period, uncontrolled working schedules due to the urgency of some cases, interacting with difficult cases and/or patients, and the wide scope of the practice. ${ }^{9}$ A few studies have reported that OMS residents and surgeons experience stress and burnout due to the nature of their work and the usual stressful work environment. ${ }^{10,11,12,19,20}$

The current study aimed to assess the level of occupational stress among OMS residents and surgeons in Saudi Arabia. This will help to develop a proper national database, compare stress levels among residents and surgeons in Saudi Arabia to stress levels in residents and surgeons in other countries, and encourage future plans to positively enhance the welfare of the practitioners and eventually improve the work environment for OMS.
The number of males who responded to the survey was significantly higher than that of females $(76.2 \%$ males versus $23.8 \%$ females). This suggests that the OMS specialty is a male predominant surgical specialty not only in Saudi Arabia but also worldwide. ${ }^{21,26}$ However, in recent years, more females have joined the field and the concept of gender discrimination is no longer valid.

Participants with more working days felt more burned out due to long working hours and constant work pressure $(P=0.004)$. Although most of the OMS residents and surgeons stated that they work five days/week, $25.5 \%$ of residents reported that they work seven days/week. This could be attributed to weekend on-call duties for residents as the first or second line where their presence in the hospital is mandatory and unexpected. Another supporting 


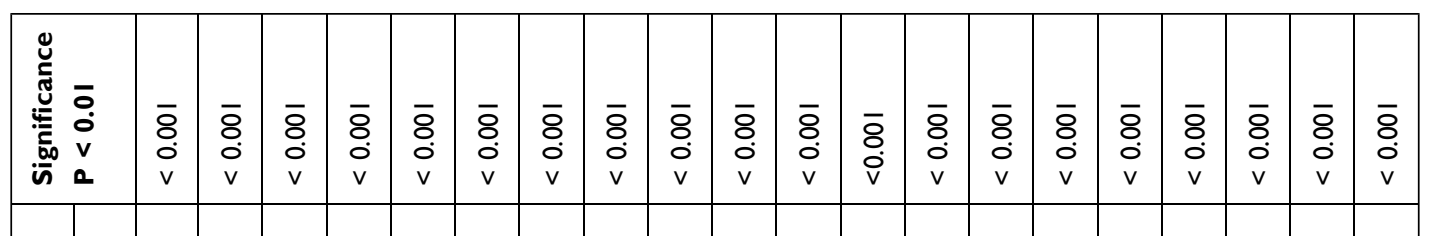

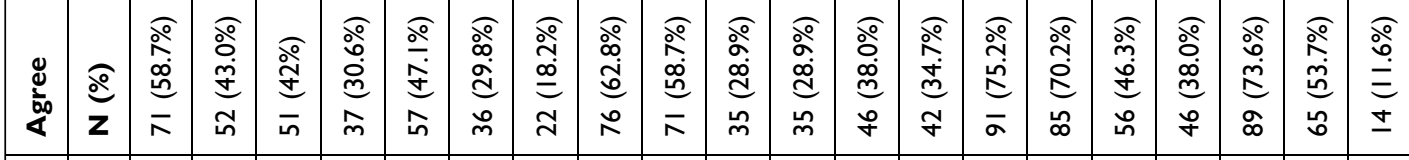

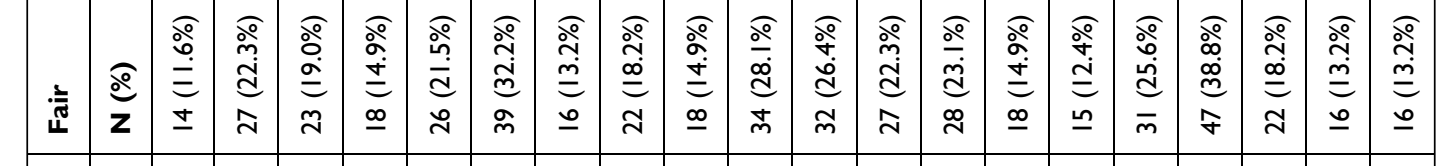

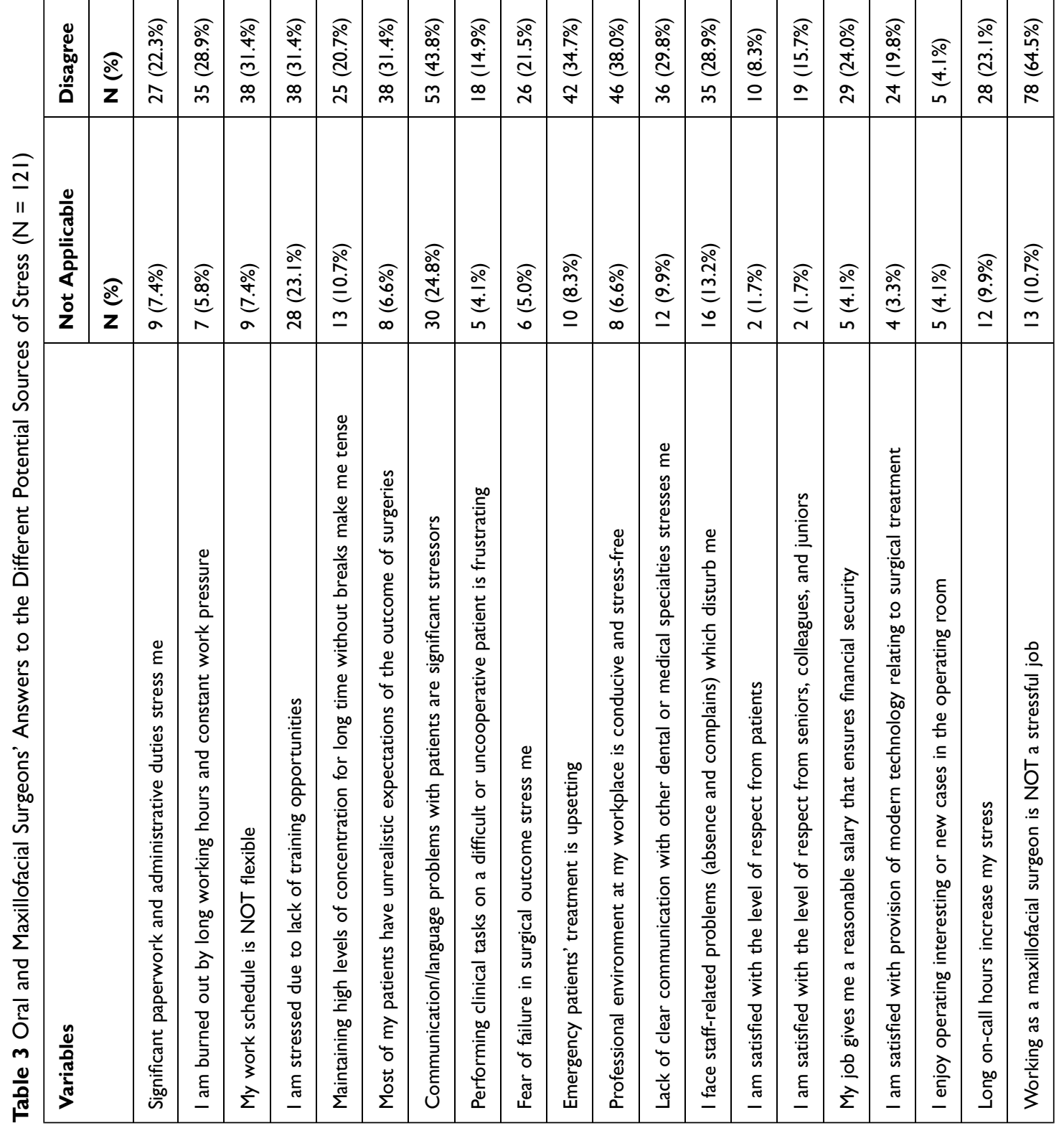




\begin{tabular}{|c|c|c|c|c|c|c|c|c|c|c|c|c|c|c|c|c|c|c|c|c|}
\hline 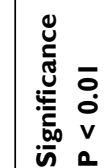 & $\begin{array}{l}\overline{8} \\
\text { o } \\
\mathrm{v}\end{array}$ & $\begin{array}{l}\overline{8} \\
\text { O } \\
\mathrm{v}\end{array}$ & $\begin{array}{l}\overline{8} \\
\text { o } \\
v\end{array}$ & $\begin{array}{l}\overline{0} \\
\text { O } \\
\mathrm{v}\end{array}$ & $\begin{array}{l}\overline{0} \\
\text { o } \\
\text { v }\end{array}$ & $\overline{0}$ & $\begin{array}{l}\overline{8} \\
0 \\
\text { v }\end{array}$ & $\begin{array}{l}\bar{\delta} \\
\dot{0} \\
\mathrm{v}\end{array}$ & $\begin{array}{l}\overline{8} \\
\dot{0} \\
\mathrm{v}\end{array}$ & $\begin{array}{l}\overline{8} \\
\text { D } \\
\mathrm{v}\end{array}$ & $\begin{array}{l}\bar{\delta} \\
\text { O. } \\
\text { v }\end{array}$ & $\begin{array}{l}\overline{8} \\
\text { o } \\
\text { v }\end{array}$ & $\begin{array}{l}\bar{\delta} \\
\dot{O} \\
\mathrm{v}\end{array}$ & $\begin{array}{l}\overline{8} \\
\text { D } \\
\mathrm{v}\end{array}$ & $\begin{array}{l}\overline{8} \\
\text { O } \\
\mathrm{v}\end{array}$ & $\begin{array}{l}\overline{\text { og }} \\
\text { v } \\
\text { v }\end{array}$ & $\begin{array}{l}\bar{\delta} \\
\dot{0} \\
\mathrm{v}\end{array}$ & $\begin{array}{l}\overline{\text { og }} \\
\text { v } \\
\text { v }\end{array}$ & $\begin{array}{l}\bar{\delta} \\
\dot{0} \\
v\end{array}$ & $\begin{array}{l}\bar{\delta} \\
0 \\
v\end{array}$ \\
\hline
\end{tabular}

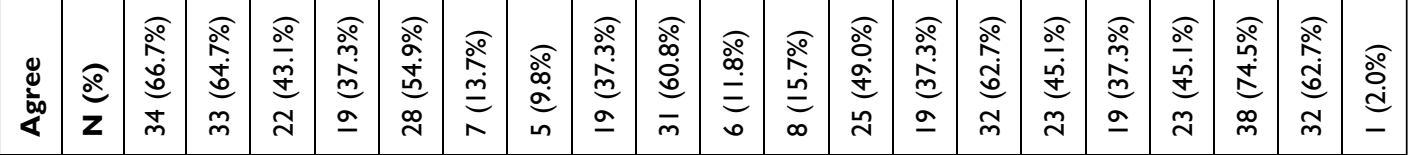

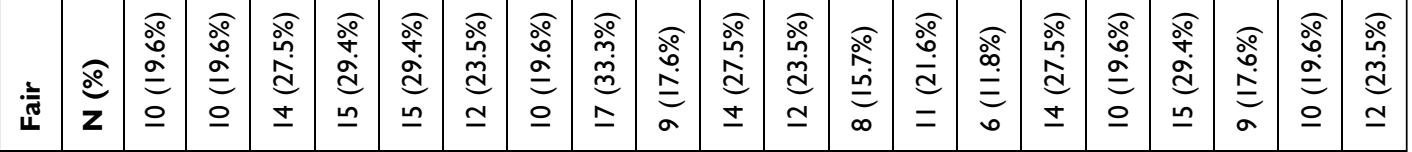

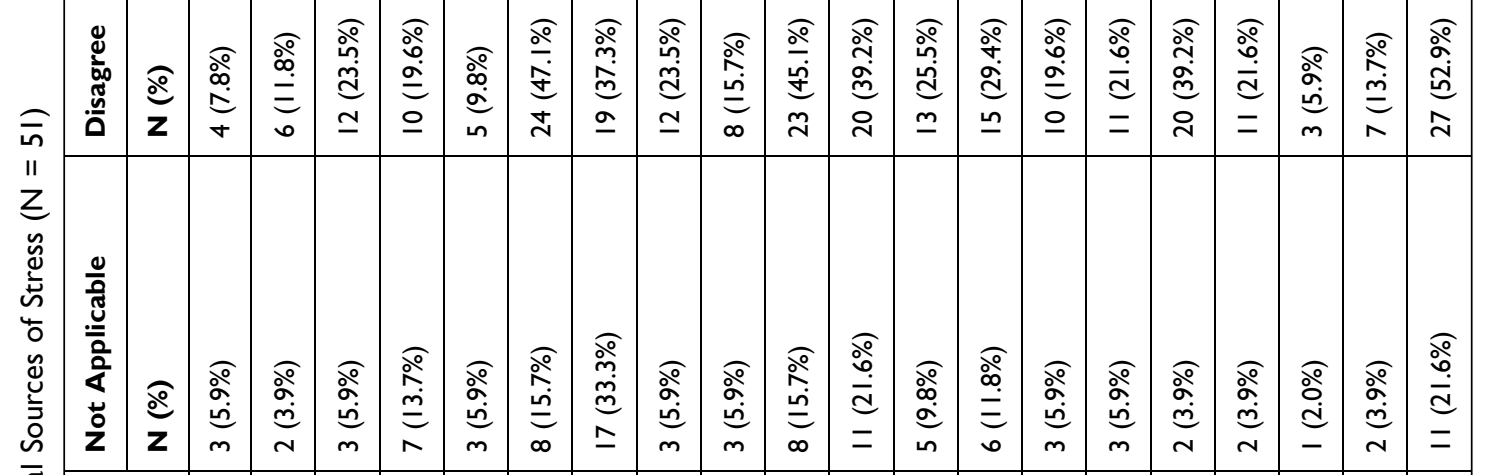

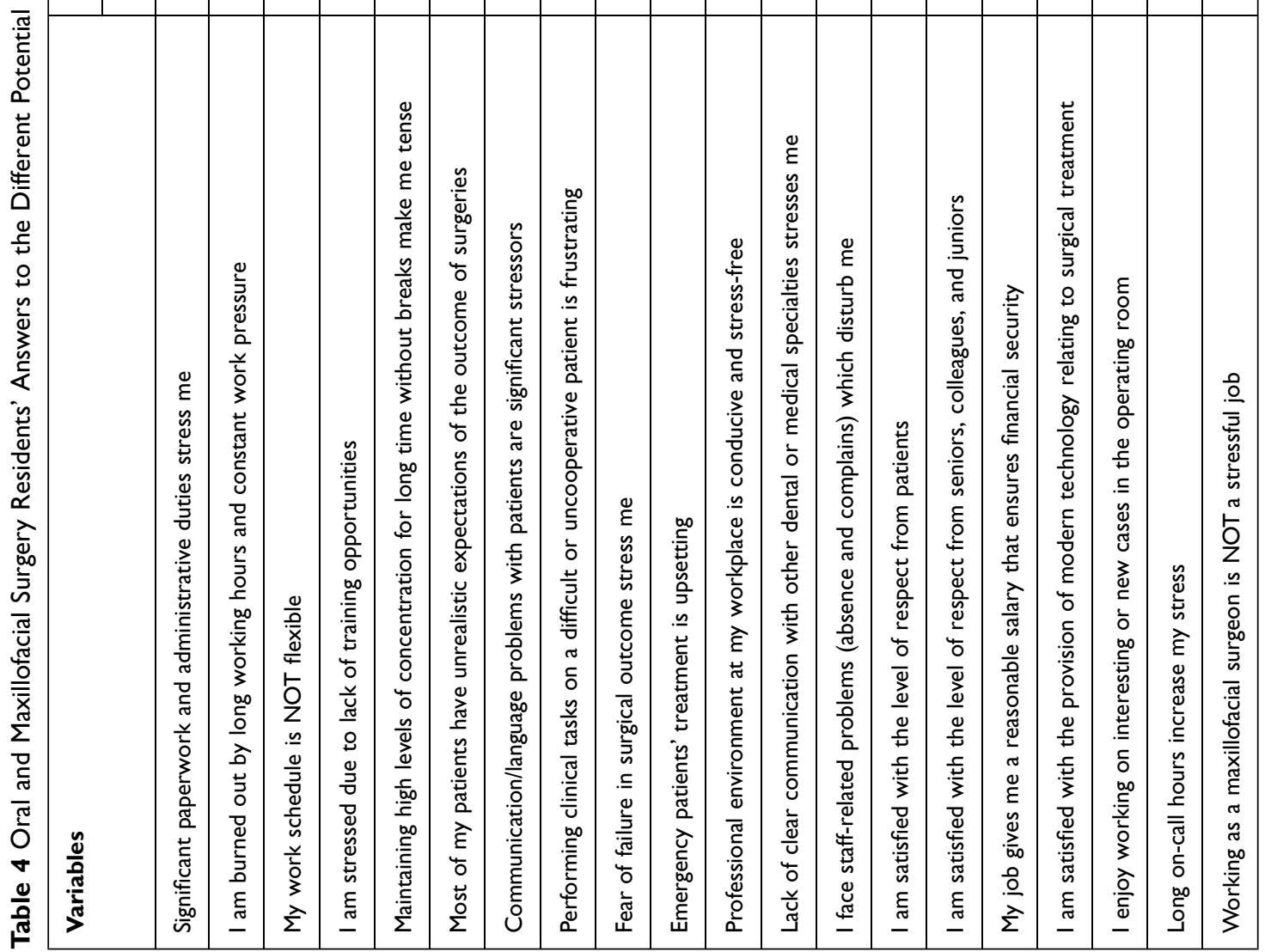


finding was that, among residents, longer on-call periods were significantly and positively correlated with increased stress levels as their work schedule was not flexible $(P=$ $0.000, r=0.564)$. Additionally, this increase in working days among residents more often contributed significantly to staff-related problems $(P=0.005)$. This suggests that there is a direct relationship between increased working days and marked stress. This relationship could negatively affect social relationships. A similar study done on orthodontists in Saudi Arabia showed that orthodontists have more control over their clinical schedules and find more time to spend with their families which provide more data that OMS is stressful among other dental specialties. ${ }^{27}$

Regarding working hours, both surgeons and residents work more than 40 hours/week, which is consistent with the findings of Porto et al, ${ }^{12}$ who reported that majority of the OM surgeons worked 30-50 hours/week. Although Contag et $\mathrm{al}^{28}$ reported that the number of working hours was not associated with the rate of burnout, in the present study, residents were more burned out due to long working hours $(P=0.003)$. Furthermore, Hameed et $\mathrm{al}^{29}$ conducted a similar study and explored the relationship between duty hours and burnout among medical residents in Saudi Arabia. They found a very high degree of burnout among medical residents, which supports the findings in this study. ${ }^{29}$ In the current study, the working hours of residents $(74 \%)$ were longer than that for surgeons (45 hours and more per week). Being the most juniors in the department, residents are assigned more duties including paperwork, following-up inpatients, and on-call hours. Suggestions were made for the development of work hour regulations in Saudi Arabia and for the development of programs to address resident burnout. ${ }^{29}$ This finding is consistent with Carneiro et $\mathrm{al}^{11}$ where OMS residents are subject to more stress and burnout due to high work and training demands and the expectations from seniors and society. Regarding the increased duty hours required by residents, a narrative review aiming to limit surgical residents' working hours did propose an overall "culture of safety," which includes identifying potential sources of error, raising performance and safety standards, and protecting against medical errors, ${ }^{30}$ and argued for a more flexible educational environment that protects resident education and ensures optimal training for the next generation of physicians and surgeons at stress-free workplaces. $^{30}$

One of the major contributing factors to burnout is the individual's perception of whether or not he or she can control a situation, including working schedules. ${ }^{31}$ A study of professionals in 3 different dental specialties, namely, orthodontics, restorative dentistry, and OMS, demonstrated that orthodontists suffered least from symptoms of depersonalization. ${ }^{32} \mathrm{OM}$ surgeons and restorative dentists, however, did not fare as well with increasing values for OM surgeons. The reason for this difference was thought to be the variable degree of control and flexibility that these specialists have over their working schedules. Orthodontists are able to interrupt their work for an emergency, and there is far less urgency to their procedures. The surgical specialties, however, are far more demanding of the practitioners' time; that is, once started, a procedure cannot be interrupted or postponed, thus increasing time pressures. $^{32}$

Due to the increase in advancements in the medical industry, both generally and in the field of OMS, in Saudi Arabia, most participants reported having three or more chairs per patient, which can increase the number of healthcare services provided and decrease the waiting time of patients. Both groups reported overall satisfaction with the level of respect they receive from their patients. On the other hand, surgeons who worked in clinics that have less chairs/patients felt less often being on top of things over the past month $(P=0.001)$. This suggests that having fewer chairs/patients could delay work and subject the clinician to more stress.

The results also suggest that the stress levels of residents usually increase when they do not have adequate training. Training opportunities for residents are mandatory to enable them to gain experience and fulfill their requirements.

Surgeons who experience less joy when working on interesting or new cases that involve general anesthesia worked on less cases per month $(P=0.000)$. Usually, surgeons who thrive to operate cases will schedule more cases under general anesthesia per month. Age is considered an important factor in the level of stress among participants. ${ }^{33}$ In the current study, older surgeons experienced less joy when working on interesting or new cases in the operating room $(P=0.005)$. This is because older surgeons mostly prefer to lower their level of stress by decreasing their workload. This is in agreement with the results of a similar study that showed that older and experienced OM surgeons experience less burnout than their younger and less experienced colleagues. ${ }^{12}$ Moreover, another study reported that more experienced 


\begin{tabular}{|c|c|c|c|c|c|c|c|c|c|c|c|}
\hline \multicolumn{2}{|c|}{ 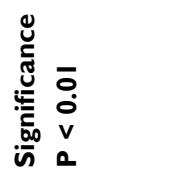 } & \multirow{2}{*}{ 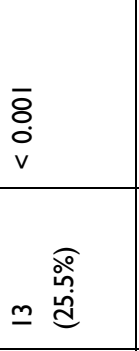 } & \multirow{2}{*}{ 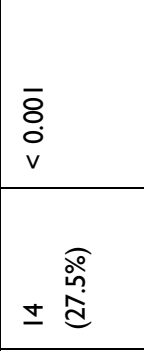 } & \multirow{2}{*}{ 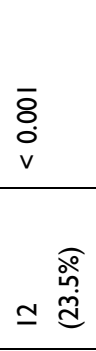 } & \multirow{2}{*}{ 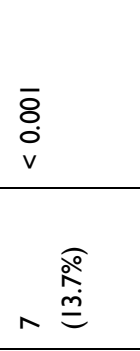 } & \multirow{2}{*}{ 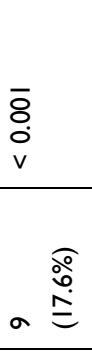 } & \multirow{2}{*}{ 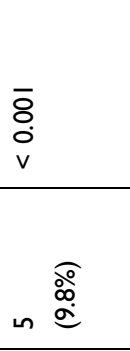 } & \multirow{2}{*}{ 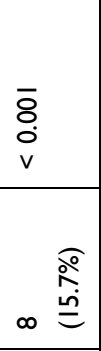 } & \multirow{2}{*}{ 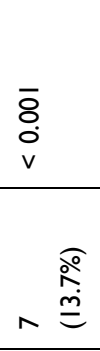 } & \multirow{2}{*}{ 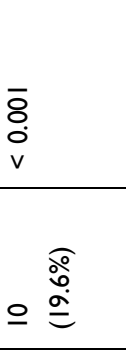 } & \multirow{2}{*}{ 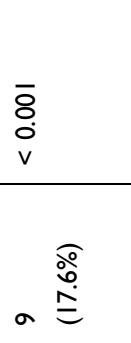 } \\
\hline & 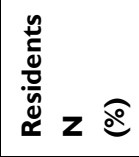 & & & & & & & & & & \\
\hline 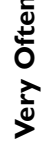 & 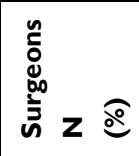 & $=\frac{\widehat{\circ}}{\stackrel{\sigma}{\sigma}}$ & $\pm \stackrel{\text { 官 }}{\Xi}$ & $\underline{\stackrel{\widehat{\circ}}{\stackrel{9}{ٍ}}}$ & م & 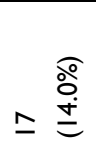 & 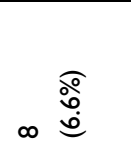 & $\approx \stackrel{\substack{\stackrel{\widehat{O}}{0} \\
\stackrel{\infty}{\infty}}}{=}$ & $\approx \stackrel{\substack{\stackrel{\circ}{\sim} \\
\stackrel{\infty}{=}}}{0}$ & 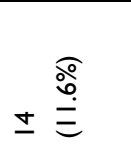 & 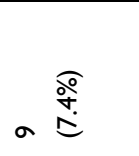 \\
\hline \multirow[b]{2}{*}{ 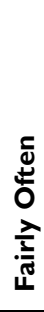 } & 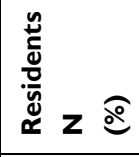 & 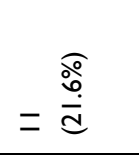 & $\simeq \stackrel{\substack{\stackrel{\circ}{0} \\
\hdashline}}{\stackrel{d}{d}}$ & 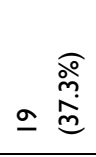 & 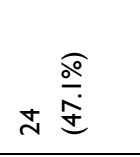 & 定 & 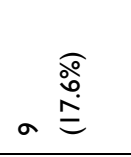 & 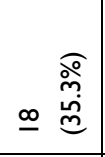 & m & 느웡 & 느웜 \\
\hline & 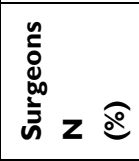 & 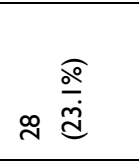 & 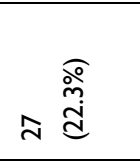 & 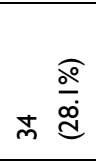 & ๖ & 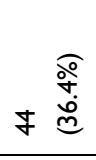 & 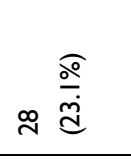 & 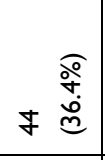 & 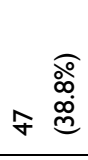 & 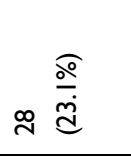 & 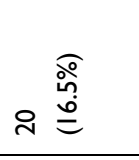 \\
\hline \multirow[b]{2}{*}{ 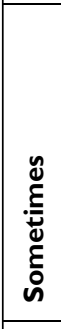 } & 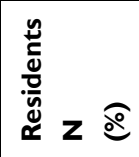 & 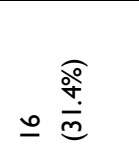 & 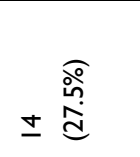 & 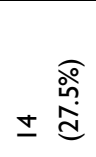 & 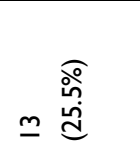 & 느 & 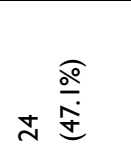 & 동 & 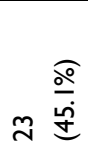 & 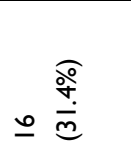 & 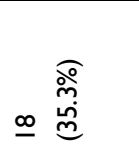 \\
\hline & 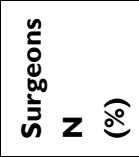 & 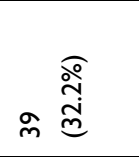 & 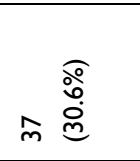 & ơ & œ & o & n & 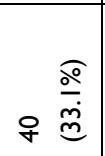 & 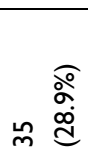 & 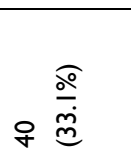 & \&) \\
\hline \multirow{2}{*}{ 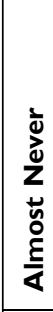 } & 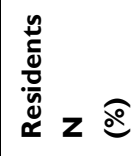 & 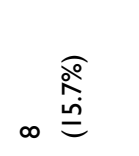 & n & + & 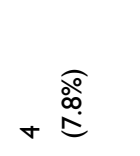 & n & 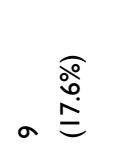 & $\infty \stackrel{\substack{\stackrel{\circ}{\circ} \\
\stackrel{\rho}{*}}}{=}$ & 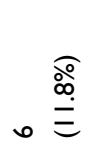 & 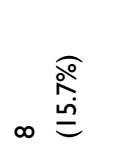 & $+\stackrel{\stackrel{\circ}{\infty}}{\stackrel{\circ}{\infty}}$ \\
\hline & 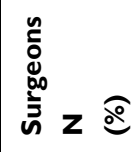 & 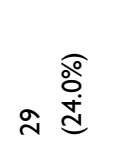 & 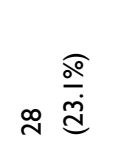 & 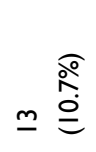 & ○ & $=\frac{\widehat{\circ}}{\sigma}$ & 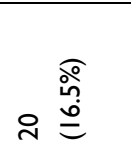 & ○ & $\simeq \stackrel{大}{\stackrel{\circ}{\sigma}}$ & 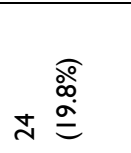 & 怘 \\
\hline \multirow[b]{2}{*}{$\begin{array}{l}\mathbf{d} \\
\overline{0} \\
\mathbf{z}\end{array}$} & 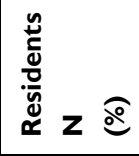 & $m$ m & 。 & 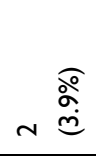 & $m$ & 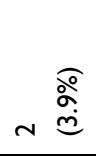 & 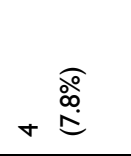 & 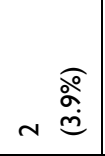 & 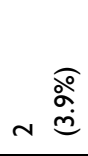 & 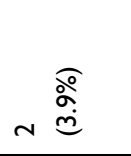 & n \\
\hline & 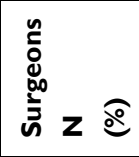 & $\pm \stackrel{\text { }}{\stackrel{\circ}{\Xi}}$ & 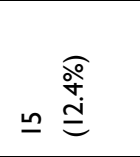 & 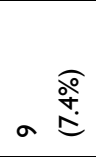 & 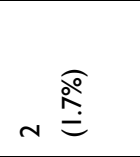 & $m \stackrel{\text { }}{\stackrel{\text { de }}{d}}$ & 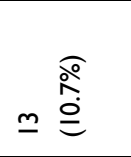 & 几 & 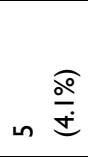 & 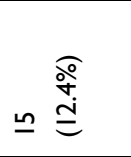 & 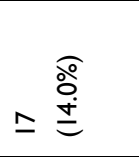 \\
\hline & 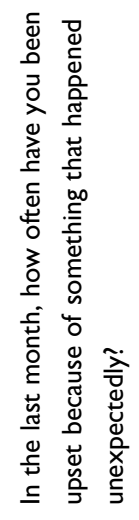 & 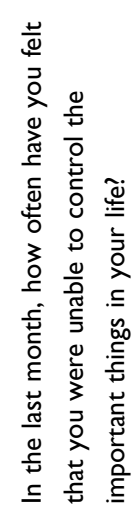 & 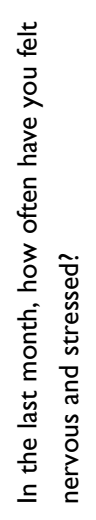 & 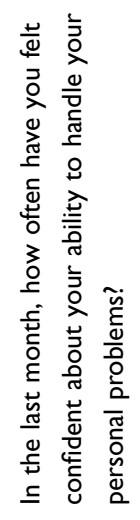 & 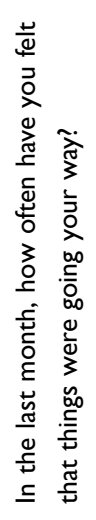 & 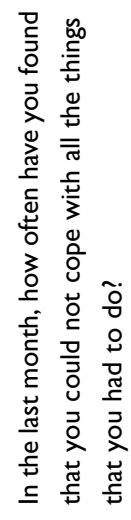 & 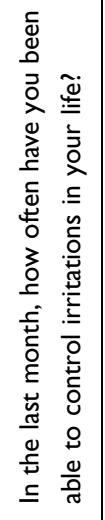 & 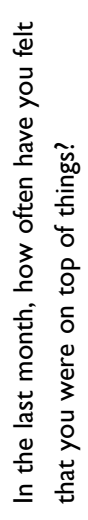 & 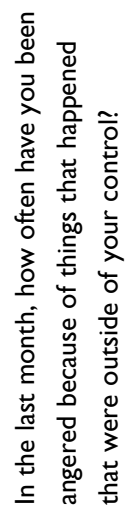 & 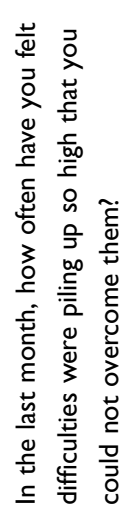 \\
\hline
\end{tabular}


Table 6 Perceived Stress Scale (PSS) Category Results

\begin{tabular}{|l|l|l|}
\hline Surgeons (N = I2I) & N & $\%$ \\
\hline Stress level Result & 30 & 24.8 \\
\hline Low stress & 84 & 69.4 \\
Moderate stress & 7 & 5.8 \\
High stress & 121 & 100.0 \\
Total & \multicolumn{2}{|l|}{} \\
\hline Residents (N = 5I) & $\mathbf{N}$ & $\%$ \\
\hline Stress level result & 5 & 9.8 \\
\hline Low stress & 40 & 78.4 \\
Moderate stress & 6 & 11.8 \\
High stress & 51 & 100.0 \\
Total & \multicolumn{2}{|l}{} \\
\hline
\end{tabular}

OM surgeons showed a higher stress management ability than surgeons with less experience. ${ }^{34}$

Fear of surgical failure was selected by surgeons and residents as a source of stress. Due to the involvement of OMS surgeons and residents in major surgeries such as jaw corrective surgeries, facial bone fractures, and pathology surgeries in the head and neck areas, OMS residents and surgeons are under immense pressure to deliver excellent functional and cosmetic results.

Clear communication between OMS residents and surgeons and those in other specialties is essential to ensure the delivery of better patient care services. In the current study, participants were stressed due to unclear communication between them and their colleagues in other dental and/or medical specialties. A recent study was conducted in Saudi Arabia to assess how well known the OMS specialty is among dental and medical practitioners, as well as the public. ${ }^{35}$ The results of the study revealed that the scope of practice of OMS was generally less known. ${ }^{35}$ So, it was concluded that lack of proper knowledge of the field can influence the communication of OMS practitioners and therefore expose them to additional stress which is consistent with the finding of the present study.

In terms of financial security, most surgeons agreed $(46.3 \%)$ that their profession ensures financial security, while $39.2 \%$ of the residents disagreed. This is because the salaries of residents are lower than those of surgeons. Additionally, some of the residents might not have jobs yet. Moreover, surgeons with less experience usually do not get promoted, hence they were less satisfied with the financial status $(P=0.002)$.
Both OMS residents and surgeons were mostly satisfied with the overall level of respect they receive from their colleagues. Residents (45.1\%) were less satisfied with the level of respect they receive from their seniors, colleagues, and juniors compared to surgeons $(70.2 \%, P=$ 0.004). This suggests that residents do not receive the same level of respect and admiration from others as surgeons in the field since they are still trainees.

Since residents are subjected to a higher amount of stress during work, the findings of this study showed that OMS residents have slightly increased stress levels compared to surgeons, according to the perceived stress scale (PSS). The mean PSS score in the current study was 17.51 for surgeons and 20.61 for residents, whereas the PSS score was estimated as 19.9 for 159 anesthesia residents in Turkey ${ }^{36} 16.1$ for 168 family medicine residents in the United States, ${ }^{37}$ and 22 for 938 different medical residents in Saudi Arabia. ${ }^{18}$ The PSS score for OMS residents in this study is higher than that reported for anesthesia and family medicine residents worldwide but lower than that reported for medical residents in Saudi Arabia. This result suggests that the degree of stress experienced by OMS residents in Saudi Arabia is almost similar to that experienced by their colleagues in other medical specialties.

Al Attasi et $\mathrm{al}^{20}$ concluded that more than half of the OMS residents in the United States experience moderate-tosevere anxiety and stress according to the Hospital Anxiety and Depression Scale and the personal Maslach Burnout Index in which it was suggested to be related to their selfcriticism and fear of falling short of their internal ideal of themselves being an ideal surgeon. The results also suggest the presence of an inverse relationship between perceived personal achievement and anxiety. ${ }^{20}$ Although different scales were used in the aforementioned study, the findings are comparable to those of the present case..$^{20}$ In both studies, OMS residents reported that they experience a moderate amount of stress, using the PSS, and increased levels of stress, using the designed questionnaire.

Overall, according to one study, it was shown that general surgeons in Saudi Arabia demonstrate more stress and depersonalization than their colleagues in other nonsurgical medical specialties, ${ }^{38}$ which supports the concept that surgical specialties in general are very demanding and pressuring. They explored the factors which were independently associated with increased likelihood of burnout and found that burnout is increased in the initial stage of medical practice, in surgical residents and surgeons, in individuals whose current job negatively affected their 
family life, and individuals who were suffering from sleep deprivation or back pain. ${ }^{38}$ Similar results were reported by another study done on medical residents in Saudi Arabia where surgical residents are more stressed than their nonsurgical colleagues. ${ }^{39}$ Most of these factors are in agreement with the present study finding, except for back pain and quality of sleep which were not investigated and can be considered a limitation of the study.

\section{Conclusion}

Both OMS residents and surgeons in Saudi Arabia are subjected to high levels of occupational stress. They are at a risk of perceived stress that is comparable to the perceived stress reported by residents and surgeons worldwide. Their stress seems to be associated with the long working days and high workload. Considering the high level of stress among professionals, the use of stress management strategies in educational programs is warranted. Due to the importance of OMS and its contribution to the healthcare industry, it is necessary to ensure a healthy working environment for practitioners and to minimize the factors that increase the level of stress. This will improve the living standards of OMS practitioners and ensure the delivery of optimal healthcare services to patients. Future studies comparing occupational stress among closely related specialties such as other surgical specialties, dentists and healthy controls are encouraged to specifically recognize the stressors in OMS.

\section{Source(s) of Support}

College of Dentistry Research Centre and the Deanship of Scientific Research at King Saud University, Saudi Arabia (registration number: FR 0509).

\section{Abbreviations}

OMS, oral and maxillofacial surgery; OM Surgeon, oral and maxillofacial surgeon; PSS, Perceived Stress Scale; DSc, Doctorate of Science; MSc, Master of Science.

\section{Acknowledgment}

The authors would like to thank the College of Dentistry Research Centre and the Deanship of Scientific Research at King Saud University, Saudi Arabia for funding this research project (registration number: FR 0509).

\section{Disclosure}

The authors report no conflicts of interest for this work.

\section{References}

1. Richardson KM, Rothstein HR. Effects of occupational stress management intervention programs: a meta-analysis. $J$ Occup Health Psychol. 2008;13(1):69-93. doi:10.1037/1076-8998.13.1.69

2. W. F. P. (WFP). WFP Emergency Field Operations Pocketbook. Rome (Italy): World Food Programme (WFP); 2002.

3. W. H. Organization. International Statistical Classification of Diseases and Related Health Problems: ICD-10. Geneva Switz: World Heal. Organ; 1992.

4. American Institute of Stress. What is Stress? Available from: https:// www.stress.org/slide/job-stress. Accessed September 26, 2020.

5. Iacovides A, Fountoulakis KN, Kaprinis S, Kaprinis G. The relationship between job stress, burnout and clinical depression. $J$ Affect Disord. 2003;75(3):209-221. doi:10.1016/S0165-0327(02)00101-5

6. Elbarazi I, Loney T, Yousef S, Elias A. Prevalence of and factors associated with burnout among health care professionals in Arab countries: a systematic review. BMC Health Serv Res. 2017;17 (1):491. doi:10.1186/s12913-017-2319-8

7. Song K-W, Choi W-S, Jee H-J, et al. Correlation of occupational stress with depression, anxiety, and sleep in Korean dentists: crosssectional study. BMC Psychiatr. 2017;17(1):398. doi:10.1186/ s12888-017-1568-8

8. Rusli B, Edimansyah B. Prevalence and associated factors of stress in dental healthcare workers of a higher institution of learning in Kelantan. Arch Orofac Sci. 2006;1:51-56.

9. LaPorta LD. Occupational stress in oral and maxillofacial surgeons: tendencies, traits, and triggers. Oral Maxillofac Surg Clin North Am. 2010;22(4):495-502. doi:10.1016/j.coms.2010.07.006

10. Humphris GM, Peacock L. Occupational stress and job satisfaction in the community dental service of north Wales: a pilot study. Community Dent Health. 1993;10(1):73-82.

11. Carneiro S, Vasconcelos B, Nascimento M, Leal J, Orestes M, Porto G. Occupational stress among Brazilian oral-maxillofacial surgeons. Med Oral Patol Oral Cir Bucal. 2009;14(12):e646-9. doi:10.4317/ medoral.14.e646

12. Porto GG, Carneiro SC, Vasconcelos BC, Nascimento MM, Leal JLF. Burnout syndrome in oral and maxillofacial surgeons: a criticalanalysis. Int J Oral Maxillofac Surg. 2014;43(7):894-899. doi:10.1016/j. ijom.2013.10.025

13. Gorter R, Jacobs B, Allard R. Low burnout risk and high engagement levels among oral and maxillofacial surgeons. Eur J Oral Sci. 2012;120:69-74. doi:10.1111/j.1600-0722.2011.00923.x

14. Lourencao LG, Moscardini AC, Soler ZASG. [Health and quality of life of medical residents]. Rev Assoc Med Bras. 2010;56(1):8191. Portuguese.

15. Veasey S, Rosen R, Barzansky B, Rosen I, Owens J. Sleep loss and fatigue in residency training: a reappraisal. JAMA. 2002;288 (9):1116-1124. doi:10.1001/jama.288.9.1116

16. Fruchtman Y, Moser AM, Perry ZH. Fatigue in medical residentslessons to be learned. Med Lav. 2011;102(5):455-463.

17. West CP, Shanafelt TD, Kolars JC. Quality of life, burnout, educational debt, and medical knowledge among internal medicine residents. JAMA. 2011;306(9):952-960. doi:10.1001/jama.2011.1247

18. Alosaimi FD, Kazim SN, Almufleh AS, Aladwani BS, Alsubaie AS. Prevalence of stress and its determinants among residents in Saudi Arabia. Saudi Med J. 2015;36(5):605-612. doi:10.15537/ smj.2015.5.10814

19. Shapiro MC, Rao SR, Dean J, Salama AR. What a shame: increased rates of OMS resident burnout may be related to the frequency of shamed events during training. J Oral Maxillofac Surg. 2017;75 (3):449-457. doi:10.1016/j.joms.2016.08.040

20. Al Atassi H, Shapiro MC, Rao SR, Dean J, Salama A. Oral and maxillofacial surgery resident perception of personal achievement and anxiety: a cross-sectional analysis. J Oral Maxillofac Surg. 2018;76(12):2532-2539. doi:10.1016/j.joms.2018.06.018 
21. Ghai S. Severe anxiety among female oral-maxillofacial surgery residents: can gender discrimination be a cause? J Oral Maxillofac Surg. 2018;76(11):2248. doi:10.1016/j.joms.2018.06.180

22. Cohen S, Kamarck T, Mermelstein R. A global measure of perceived stress. J Health Soc Behav. 1983;24:386-396. doi:10.2307/2136404

23. Roth SF, Heo G, Varnhagen C, Glover KE, Major PW. Occupational stress among Canadian orthodontists. Angle Orthod. 2003;73(1):43-50.

24. Lwanga K, Lemeshow S; Geneva World Health Organisation. Sample size determination in health studies a practical manual sample size determination in health studies: a practical manual. Health Serv Manag Res. 1991;4(3):230.

25. Rocha NS, Laureano Filho JR, Silva EDO, Almeida RCA. Perception of oral maxillofacial surgery by health-care professionals. Int J Oral Maxillofac Surg. 2008;37(1):41-46.

26. Marti KC, Lanzon J, Edwards SP, Inglehart MR. Career and professional satisfaction of oral and maxillofacial surgery residents, academic surgeons, and private practitioners: does gender matter? J Dent Educ. 2017;81(1):75 LP- 86. doi:10.1002/j.0022-0337.2017.81.1. tb06249.x

27. Alqahtani ND, Alshehry K, Alateeq S, et al. An assessment of job satisfaction: a cross-sectional study among orthodontists of Saudi Arabia. J Orthod Sci. 2018;7(1):4. doi:10.4103/jos.JOS_77_17

28. Contag SP, Golub JS, Teknos TN, et al. Professional burnout among microvascular and reconstructive free-flap head and neck surgeons in the United States. Arch Otolaryngol Head Neck Surg. 2010;136 (10):950-956. doi:10.1001/archoto.2010.154

29. Hameed TK, Masuadi E, Al Asmary NA, Al-Anzi FG, Al Dubayee MS. A study of resident duty hours and burnout in a sample of Saudi residents. BMC Med Educ. 2018;18(1):180. doi:10.1186/s12909-0181300-5

30. Fabricant PD, Dy CJ, Dare DM, Bostrom MP. A narrative review of surgical resident duty hour limits: where do we go from here? J Grad Med Educ. 2013;5(1):19-24. doi:10.4300/JGME-D-12-00081.1
31. Hakanen J. Job engagement and burnout. Psykologia. 2002;37:291301.

32. Humphris G, Lilley J, Kaney S, Broomfield D. Burnout and stressrelated factors among junior staff of three dental hospital specialties. Br Dent J. 1997;183(1):15-21. doi:10.1038/sj.bdj.4809420

33. Chen Y, Peng Y, Xu H, O'Brien W. Age differences in stress and coping: problem-focused strategies mediate the relationship between age and positive affect. Int J Aging Hum Dev. 2017;86:009141501772089.

34. Marrelli M, Gentile S, Palmieri F, Paduano F, Tatullo M, Bencharit S. Correlation between Surgeon's experience, surgery complexity and the alteration of stress related physiological parameters. PLoS One. 2014;9(11):e112444. doi:10.1371/journal.pone.0112444

35. Alnofaie H, Alchawaf B, AlKindi M. Knowledge, awareness, and perception of oral and maxillofacial surgery among the public and professionals in Saudi Arabia: a cross-sectional study. Int $J$ Oral Maxillofac Surg. 2019;48(12):1597-1603. doi:10.1016/j. ijom.2019.06.019

36. Abut Y, Kitapcioglu D, Erkalp K, Toprak N, Boztepe A, Sivrikaya U. Job burnout in 159 anesthesiology trainees. Saudi J Anaesth. 2012;6:46-51. doi:10.4103/1658-354X.93059

37. Lebensohn P, Dodds S, Benn R, Brooks A, Birch M, Cook P. Resident wellness behaviors: relationship to stress, depression, and burnout. Fam Med. 2013;45:541-549.

38. Aldrees T, Hassouneh B, Alabdulkarim A, et al. Burnout among plastic surgery residents. National survey in Saudi Arabia. Saudi Med J. 2017;38(8):832-836. doi:10.15537/smj.2017.8.18346

39. Bahnassy A, Saeed A, Almatham K, Moazen M, Abdulkarim Y. Stress among residents in a tertiary care center, Riyadh, Saudi Arabia: prevalence and associated risk factors. Prensa Med Argent. 2018;104(6).
Advances in Medical Education and Practice

\section{Publish your work in this journal}

Advances in Medical Education and Practice is an international, peerreviewed, open access journal that aims to present and publish research on Medical Education covering medical, dental, nursing and allied health care professional education. The journal covers undergraduate education, postgraduate training and continuing medical education
Dovepress

including emerging trends and innovative models linking education, research, and health care services. The manuscript management system is completely online and includes a very quick and fair peer-review system. Visit http://www.dovepress.com/testimonials.php to read real quotes from published authors.

Submit your manuscript here: http://www.dovepress.com/advances-in-medical-education-and-practice-journal 